\title{
Correspondence
}

\section{Computerised literature searches - how complete?}

\section{DeAR SiRs}

Trainee doctors, particularly in hospital specialities, are becoming increasingly aware of the pressing need to publish research in order to progress in their chosen branch of medicine. Recent papers, notably in the psychiatric literature, have shown that to progress up from one grade to the next is substantially more difficult without research; the number and, to an extent, the type of publications on trainees' CVs significantly affecting their likelihood of success (Katona \& Robertson, 1993; Lewis, 1991).

Many trainees, in response to this "publish or be damned" message, rush into research, possibly leading to a substandard result. In the BMJ last year there were items relating to the quality of research in medical journals (Dixon, 1992; Haynes, 1992) and to errors in reviews of published reports (i.e., literature searches) included in such papers, throwing their overall value into question (Jones, 1992). The use of a bibliographic searching tool such as MEDLINE on CD-ROM has been suggested as the possible solution to the latter problem.

Those with access to the MEDLINE programme will no doubt feel that it has made an enormous difference to the speed of literature searches. It is not easy, however, to be sure of the completeness of one's work when using such a tool. One is often surprised to find a familiar, apparently important, paper not cited. Unfortunately, it is not possible to "ask" the computer for details about what information is available to, or being accessed by, the user. How many journals are covered? Which supply most citations? How many and which journals relevant to one's specific area of interest are cited in the program?

My investigations, as part of a comparison of MEDLINE with another programme, have led to some answers. For the most recent disc (1987 to present), I found 3,946 journals listed as providing cited articles, as of the end of 1991. Of these, 107 were of primarily psychiatric/psychological content and 63 of probable relevance to these areas. (The former having words such as 'psychiatric', 'psychological', or 'psychopharmacology' or subject titles, e.g., 'drug addiction', as part of their title; the latter being general, e.g., BMJ and Lancet, or neurological/other pharmacological.)

A "Top 10" of journals in the former group, their position being dependent upon the number of cited articles from them is:
1. American Journal of Psychiatry
Citations
2,249
2. British Journal of Psychiatry
1,903
3. Journal of Neurology, Neurosurgery and Psychiatry
1,675
1,336
1,219
5. Biological Psychiatry
$\begin{array}{lr}\text { 6. Hospital and Community Psychiatry } & 1,111 \\ \text { 7. Journal of Clinical Psychiatry } & 989\end{array}$
8. Acta Psychiatrica Scandivanica
927
829
9. British Journal of Addiction
776

Although MEDLINE compares favourably with other bibliographic searching tools, there is a need for information about content to be readily available. When using such a system one is not, after all, accessing an entire universe of literature - merely a selection.

The quantity of citations from different journals will also affect which journals are requested most often by users of the program, thus being important information for libraries. My own university medical library takes only five of the above "Top 10", for example.

Such descriptive data relating to content of computerised bibliographic searching tools are extremely important and should be easily available when using these programs. If not, the user may be making as complete a search as possible but from a database about which he or she knows virtually nothing.

Peter J. TrigWell

St James's University Hospital

Beckett Street, Leeds LS9 7TF

\section{References}

Dixon, B. (1992) Serious errors in serious journals. British Medical Journal, 304, 1120.

HAYNES, R. B. (1992)Clinical review articles. British Medical Journal, 304, 330-331.

JONES, R. (1992) Searching published reports. British Medical Journal, 304, 316.

KATONA, C. L. E. \& ROBERTSON, M. (1993) Who makes it in psychiatry: CV predictors of success in training grades. Psychiatric Bulletin, 17, 27-29.

LEwIS, S. (1991) The right stuff? A prospective controlled trial of trainees' research. Psychiatric Bulletin, 15, 478-480.

\section{Research for psychiatrists in training}

DeAr SiRs

Since the College devoted a session of the Autumn quarterly meeting to research in 1980 , it has been 